\title{
PRODUTIVIDADE DE BANANEIRA "NANICA" EM RESPOSTA Á DOSES E FONTES DE FÓSFORO: AVALIAÇÃO DO $5^{\circ} \mathrm{CICLO}$
}

\author{
Cleber Gonçalves Brito ${ }^{1}$ \\ Kivison Raysllan Ferreira Sobral ${ }^{2}$ \\ Fernando Araújo da $\mathrm{Cruz}^{3}$ \\ Rodrigo Nogueira Martins ${ }^{4}$ \\ José Ângeles Moreira de Oliveira ${ }^{5}$ \\ Juscelina Leite Ferreira Neta ${ }^{6}$ \\ Melissa Maria da Silva Souza ${ }^{7}$ \\ Dilermando Dourado Pacheco ${ }^{8}$
}

Resumo O cultivo da bananeira no norte de Minas Gerais necessita de irrigação para atender a elevada demanda hídrica da planta. Contudo, a água disponível para tal objetivo geralmente é calcária e induz a desequilíbrios, principalmente de fósforo $(\mathrm{P})$, no solo e na planta, diminuindo o crescimento e o vigor dos bananais, consequentemente influenciando na produtividade da cultura. O objetivo do presente trabalho foi determinar o efeito de doses $0,5,10,20$ e $30 \mathrm{~g}$ de $\mathrm{P}_{2} \mathrm{O}_{5}$ por "família", testando as fontes de fosfato monoamômico (MAP) e superfosfato simples (SS), sobre a produtividade da bananeira "Nanica" (Mussa ssp) em área irrigada com água calcária. A avaliação consistiu na mensuração do peso do cacho para estimativa da produtividade, do número de frutos e de pencas por cacho. Na avaliação dos resultados a produtividade quanto o número de frutos e de pencas por cacho não foram influenciados pelas doses do adubo fosfatado, mas a média estimada em plantas adubadas com MAP foram superiores às encontradas em plantas tratadas com SS.

Palavras-chave: Mussa ssp; Adubação fosfatada; Água subterrânea; Produção.

\footnotetext{
${ }^{1}$ Instituto Federal do Norte de Minas Gerais - IFNMG Campus Januária - Departamento de Engenharia Agrícola e Ambiental, Brasil. E-mail: eaa_cleber@hotmail.com.

${ }^{2}$ Instituto Federal do Norte de Minas Gerais - IFNMG Campus Januária - Departamento de Engenharia Agrícola e Ambiental, Brasil. E-mail: kivisoncefet@yahoo.com.br.

${ }^{3}$ Instituto Federal do Norte de Minas Gerais - IFNMG Campus Januária - Departamento de Engenharia Agrícola e Ambiental, Brasil. E-mail: fcaraujo16@hotmail.com.

${ }^{4}$ Instituto Federal do Norte de Minas Gerais - IFNMG Campus Januária - Departamento de Engenharia Agrícola e Ambiental, Brasil. E-mail: rodrigonmartins@hotmail.com.

${ }^{5}$ Instituto Federal do Norte de Minas Gerais - IFNMG Campus Januária - Departamento de Engenharia Agrícola e Ambiental, Brasil. E-mail: j.ngeles@yahoo.com.

${ }^{6}$ Instituto Federal do Norte de Minas Gerais - IFNMG Campus Januária - Departamento de Engenharia Agrícola e Ambiental, Brasil. E-mail: ju-leite021@hotmail.com.

${ }^{7}$ Instituto Federal do Norte de Minas Gerais - IFNMG Campus Januária - Departamento de Engenharia Agrícola e Ambiental, Brasil. E-mail: melissamariaita@gmail.com.

${ }^{8}$ Doutor em Fitotecnia, Instituto Federal do Norte de Minas Gerais - IFNMG Campus Januária - Departamento de Engenharia Agrícola e Ambiental, Brasil. E-mail: ddpacheco.agro@gmail.com.
} 